\title{
Nova retòrica i pràctica d'escriptura en Ramon Llull
}

\author{
Lola Badia \\ Centre de Documentació Ramon Llull. Universitat de Barcelona \\ lola.badia@ub.edu
}

\section{Resum}

El punt de referència d'aquest treball és un opuscle escrit en català l'any 1301 durant un viatge a Xipre: la Retòrica nova. Entre 1271 a 1301 Llull havia escrit les Arts de la primera fase, les primeres formulacions de les de la segona i la pràctica totalitat de les seves obres en vulgar d'expressió literària: el Llibre de contemplació en Déu, el Llibre del gentil e dels tres savis, el Romanç de Blaquerna amb el "Llibre d'amic e amat», el Llibre de Meravelles amb el "Llibre de les bèsties", el Llibre de Santa Maria, el Plant de la Verge, el Desconhort, i el Cant de Ramon. Aquests materials constitueixen l'experiència d'escriptor de Ramon Llull des de la qual es va atrevir a reformular els principis de la retòrica des d'una perspectiva congruent $\mathrm{amb}$ la pràctica de la seva producció. Resulten especialment rellevants les incursions lul.lianes en la ficció al-legòrica (1274) i l'autocomentari poètic (1299).

Paraules clau: retòrica; pràctica d'escriptura; aplicació de l'Art de Ramon Llull; ficció al.legòrica; autocomentari poètic.

\begin{abstract}
The reference for this work is a booklet written in Catalan in 1301 during a trip to Cyprus: the New Rhetoric. From 1271 to 1301, Llull wrote the Arts of the first phase, the first formulations of the second phase and practically all of his works in vulgar literary expression: the Llibre de contemplació en Déu (Book of Contemplation of God), the Llibre del gentil e dels tres savis (Book of the Gentile and the Three Wise Men), the Romanç de Blaquerna (Blanquerna) with the "Llibre d'amic e amat» ("The Book of the Lover and the Beloved»), the Llibre de Meravelles (The Book of Marvels) with the «Llibre de les bèsties» ("Book of the Beasts»), the Llibre de Santa Maria (The Book of the Virgin Mary), the Plant de la Verge, the Desconhort, and the Cant de Ramon (The Song of Ramon). These materials constitute Ramon Llull's experience as a writer from which he dared to reformulate the principles of rhetoric from a perspective that was congruent with the practice of his production. Especially relevant are the lullian incursions into allegorical fiction (1274) and poetic auto-commentary (1299).
\end{abstract}

Keywords: Rhetoric; writing practice; Application of Ramon Llull's Art; allegorical fiction; poetic auto-commentary. 
La imposant presència de Dante Alighieri en el marc de les Jornades en què s'inclou aquesta aportació convida a repensar les teories retòriques de Ramon Llull des de la perspectiva de la seva experiència d'escriptor. La crítica més recent deixa clar que no es poden entendre ni el Convivio ni el De vulgari eloquentia si, a més de connectar-los amb la trajectòria de poeta líric de Dante, no es posen en relació amb la gestació de la Commedia. ${ }^{1}$ La singular reforma de la retòrica que va proposar Llull és posterior a la redacció d'un gruix important i variat d'obres doctrinals i literàries; el punt de referència és un opuscle escrit en català l'any 1301 durant un viatge a Xipre: la Retòrica nova. ${ }^{2}$

El fet que l'Art de Ramon hagi estat descrita com una autoritat alternativa dóna raó de la gosadia que representa elaborar-ne una aplicació capaç de prendre el lloc de la tradició escolar basada en la Institutio oratoria de Quintilià i la Retorica ad Haerennium pseudociceroniana. ${ }^{3}$ Entre 1271 a 1301 Llull havia escrit les Arts de la primera fase, les primeres formulacions de les de la segona i la pràctica totalitat de les seves obres en vulgar d'expressió literària: el Llibre de contemplació en Déu, el Llibre del gentil e dels tres savis, el Romanç de Blaquerna amb el «Llibre d'amic e amat», el Llibre de Meravelles amb el "Llibre de les bèsties», el Llibre de Santa Maria, el Plant de la Verge, el Desconhort, i el Cant de Ramon. Justament després de 1301 la preferència per l'expressió llatina arracona gairebé del tot l'ús del vulgar. ${ }^{4}$

Llull havia practicat gairebé tots els gèneres romànics i havia treballat en la redacció de tractats tècnics llatins de les disciplines més diverses — de la teologia a la medicina- $\mathrm{i}$ dirigits a públics tant universitaris com laics. Tot i que descriu la nova retòrica a partir de principis generals i no la posa explícitament en relació a la seva experiència, no són difícils de descobrir els punts de contacte entre la teoria que proposa i la seva pròpia escriptura: l’opus

1. Em refereixo a la introducció a Dante Alighieri, «De vulgari eloquentia», dins Marco Santagata, Claudio Giunta, Guglielmo Gorni, Mirko Tavoni (a cura de), Opere, Milano: Mondadori («I Meridiani»), 2011. Per a una aproximació al perfil de Dante i de Llull com a cappares de les tradicions literàries italiana i catalana, cfr. el dossier «Dante i Llull: mestres de llengua i literatura?», Mot So Razo, n. 10-11, 2011-2012, p. 85-120.

2. Només ha sobreviscut la versió llatina: Ramon Llull, Rhetorica nova, Jaume MedinA (ed.), ROL XXX, 2005, p. 1-77; Ramon Llull, Retòrica nova, Josep Batalla, Lluís Cabré i Marcel OrTín (ed.), Turnhout-Santa Coloma de Queralt: Brepols-Obrador Edèndum, 2006 (Traducció de l'Obra Llatina de Ramon Llull, 1 [= TOLR]).

3. Anthony Bonner, «L'Art lul.liana com a autoritat alternativa», SL, n. 33, 1993, p. 15-32; Anthony Bonner, The Art and Logic of Ramon Llull. A User's Guide, Leiden-Boston: Brill, 2007. «Studien und Texte zur Geistesgeschichte des Mittelalters, 95». Trad. catalana: L'Art i la logica de Ramon Llull. Manual d'ús, Barcelona-Palma: Universitat de Barcelona-Universitat de les Illes Balears («Col-lecció Blaquerna», 9), 2012.

4. Lola BADIA, Teoria i pràctica de la literatura en Ramon Llull, Barcelona: Quaderns Crema, 1992; Elena PIstolesi, "Appunti su retorica e traduzione nell'opera di Ramon Llull», dins Actes de les Jornades lul.lianes en homenatge a J.N. Hillgarth $i$ Anthony Bonner (Palma 2010), Barcelona-Palma de Mallorca: Universitat de Barcelona-Universitat de les Illes Balears («Col-lecció Blaquerna», 10), p. 313-327. 
lul-lià és un tot autònom tancat en ell mateix, subordinat a l'Art, en el qual destaquen les recurrències, la continuïtat de temes i motius i l'autoreferencialitat. $^{5}$

Fent ús de la terminologia del beat, s'ha confegit l'etiqueta «nova literatura lul.liana». ${ }^{6}$ L'adjectiu «nou» situa els seus poemes, novel.les, diàlegs, exemples i proverbis entre les aplicacions de l'Art. El substantiu «literatura» designa la dilatada experiència d'escriptura de Llull, en el benentès que mai no va produir textos que avui considerem literaris com un fi en ell mateix, sinó que es va servir de l'expressió literària per a la difusió del seu missatge salvífic i la propagació de la seva missió de conversió dels infidels. No hi ha dubtes a propòsit de l'ús que Llull fa de la seva nova literatura: és un ús alternatiu, al servei de la difusió l'Art. La literatura és una «ancilla Artis».?

\section{La ficció al-legòrica (1274) i l'autocomentari poètic (1299)}

El Llibre de contemplació en Déu és l'opera prima lul.liana, que es conserva en català i en llatí i que Llull afirma haver redactat originàriament en àrab. Els capítols 352-357 es troben al tercer volum, dintre de l'última distinció, la 40 (capítols 316-364), que tracta de l'oració. És el punt culminant de tota l'obra, la «punta de l'iceberg» del "millor llibre del món per a la conversió dels infidels». ${ }^{8}$ A la quarantena distinció s'exposen, en efecte, les virtuts essencials de Déu amb un ús important de la notació literal per conduir el lector cap a la comprensió d'una matèria tan alta: som a l'origen de les figures de l'Ars compendiosa inveniendi veritatem. ${ }^{9}$ Llull ofereix també un desplegament divers de mètodes per elevar les tres potències de l'anima més amunt de l'horitzó

5. Vegeu les autocitacions recollides al catàleg d'obres de la Llull DB: <http://orbita.bib. ub.es>.

6. Per una justificació extensa de l'etiqueta, Lola Badia, Joan Santanach i Albert Soler, "Ramon Llull», dins Història de la literatura catalana, I, Barcelona: Enciclopèdia CatalanaEditorial Barcino-Ajuntament de Barcelona, 2013, p. 377-476. El punt de partida és Jordi Rubió i BALAguer, «L'expressió literària en l'obra lul.liana», dins ID., Ramon Llull $i$ el lullisme, Barcelona: Generalitat de Catalunya-Publicacions de l'Abadia de Montserrat, 1985, p. 300-314 (Obres Completes de Jordi Rubió i Balaguer, II). Cfr. Lola BADIA, «La literatura alternativa de Ramon Llull: tres mostres», dins Santiago Fortuño i Tomàs Martínez (a cura de), Actes del VII Congrés de l'Associació Hispànica de Literatura Medieval (Castelló de la Plana, 1997), I, Castelló de la Plana: Publicacions de la Universitat Jaume I, 1999, p. 11-32.

7. Lola BADIA, «Literature as an ancilla Artis: The Transformation of Science into Literature According to Robert Pring-Mill and Ramon Llull», Hispanic Research Journal, n. 10.1, 2009, p. 18-28.

8. Josep Enric Rubio, Les bases del pensament de Ramon Llull. Els orígens de l'Art lul.liana, València: Institut Interuniversitari de Filologia Catalana-Barcelona: Publicacions de l'Abadia de Montserrat, 1997, p. 59.

9. Josep Enric Rubio, «Una incursió lul.liana en l'ars memoriae clàssica al Llibre de contemplació en Déu», dins Joan Mas, Joan Miralles i Pere Rosselló (ed.), Actes de l'Onzè Col.loqui Internacional de Llengua i Literatura Catalanes (Palma 1998), I, Barcelona: Publicacions de l'Abadia de Montserrat, 1998, p. 61-72. 
humà, que acaben amb una art de disputar amb l'infidel i una art de manifestar la veritat, que té en compte, entre altres consideracions, la bellesa de les paraules. ${ }^{10}$

Els sis capítols del grup 352-357 desenvolupen una extensa construcció inspirada en els quatre sentits de l'Escriptura de l'exegesi bíblica: el literal, l'al.legòric, el tropològic o moral i l'anagògic o místic. ${ }^{11}$

Com sien quatre exposicions, estorial e tropologia e al-legoria e anagogia, nós, Sényer no tractam en est lloc de l'estorial, mas de la moral majorment qui és tropologia; mas com en romanç apellam la tropologia moral exposició, per ço car és més vulgar a les gents qui no saben llatí, per açò apellam tota l'exposició moral figura entel-lectual, en la qual figura pot hom haver coneixença de la figura d'al-legoria e d'anagogia. ${ }^{12}$

Llull presenta el mètode al-legòric en dues fases, una de teòrica i una de pràctica. Als capítols 352, 353 i 357, els teòrics, aprofita el poder polisèmic dels sentits de l'Escriptura per proposar un procediment heurístic de tres nivells de significació que permet l'elevació de la ment des de les coses sensuals fins a les espirituals i, d'aquestes, fins a la contemplació de la divinitat, la producció de pregàries belles i devotes i a la comprensió del misteri de la transubstanciació. Aquesta teoria va acompanyada d'una aplicació pràctica als capítols 354, 355 i 356, en què es presenten tres relats que demanen ser interpretats segons aquest nou mètode, que Llull confessa haver recollit d'una font àrab: «'exposició moral la qual és apellada en llengua aràbiga rams, qui és aitant a dir com moral o al.legoria o anigogia exposició». ${ }^{13}$

El terme àrab rams designa un ventall extens de sentits figurats de la parla corrent i també dels llenguatges especialitzats de la retòrica i fins de les arts divinatòries. ${ }^{14}$ Fins ara no ha estat possible precisar amb més exactitud cap font concreta de la teoria lul.liana de l'al-legoria aplicada a la contemplació. Als capítols 352 i 353 Llull observa que l'enteniment pot extreure el sentit correcte dels mots més enllà de la literalitat — sempre enganyosa i canvianti iniciar així el camí del coneixement que condueix les criatures al Creador. El mateix Llull introdueix la seva proposta explicant que si hom associa els termes — les imatges corresponents - braç, ull i foc respectivament a les nocions de poder, saviesa i amor, s’obté el pas del nivell de significació sensual al nivell

10. Cfr. Pistolesi, «Appunti su retorica», cit., nota 15.

11. Henri de Lubac, Exégèse médiévale. Les quatre sens de l'Écriture, 4 vol., Paris: Aubier, 19591964.

12. Primer paràgraf del cap. 357, Ramon Llull, Llibre de contemplació en Déu, a cura de Antoni Sancho i Miquel Arbona, dins Obres Essencials [=OE], II, Barcelona: Selecta, 1960, p. 1204.

13. Setè paràgraf del cap. 352, ibid., p. 1181.

14. El terme "rams" és un dels raríssims mots transcrits directament de l'àrab de tot l'opus lul.lià; "parce que ce sont des technicismes dont la traduction exige des péripharases», Dominique Urvor, Penser l'Islam, Les présupposés islamiques de l' Art» de Lull, París: Vrin, 1980 , p. 156. 
de significació intel-lectual. Les paraules o les imatges dels objectes físics són, així, figures que signifiquen els continguts intel-lectuals. La funció de l'allegoria és establir una correspondència entre el nivell sensual i l'intel-lectual: la sensualitat significa la intel.lectualitat. Si, partint del nivell intel-lectual, la ment és capaç de copsar el poder, la saviesa i l'amor de l'essència divina, l'estímul sensual inicial del braç, l'ull i el foc físics haurà acomplert la seva funció inductora del coneixement transcendent a través del poder de la significació. ${ }^{15}$ El nivell de significació al-legòric —és a dir, els conceptes de poder, saviesa i amor- és un element instrumental que fa de pont entre el signe físic i el significat transcendent.

El desplegament teòric del capítol 352 és d'una complexitat creixent perquè Llull investiga la manera d'extreure matisos subtils de significació a partir de paraules i d'imatges que, evidentment, no poden ser tan estàtiques i immediates com el braç, l'ull i el foc. Apareixen, així, una cambra, un ciri i un portal que signifiquen la memòria, l'enteniment i la voluntat, $i$ es descriu un joc de conflictes derivats de si la cambra és buida o és plena, el ciri és apagat o encès, i la porta és oberta o tancada. Llull introdueix en la seva investigació de les funcions de l'al-legoria procediments d'associació entre imatges i conceptes procedents de les arts de la memòria vinculades a la disciplina escolar de la retòrica, ben conegudes al segle XIII. Això és el que fa encara més complex el capítol 353, en què, d'entrada, la memòria correspon a tres cambres, l'enteniment a tres caps i la voluntat a tres peus. Cada un dels elements d'aquesta primera sèrie de ternes s'associa a d'altres imatges. Les tres cambres de la memòria, per exemple, corresponen a un palau amb totes les dependències (cambra de dormir, cuina, estable, església); els caps, a tres menes de caps diferents, i igualment els tres peus, a tres menes de peus diferents. Les dependències del palau, que són l'element manllevat de les arts de la memòria, serveixen per retenir a la ment la funció de les altres imatges que tracen el recorregut cap al coneixement superior. Al final apareixen combinacions creuades de les diverses imatges; per exemple, un llibre obert que deixa veure al seu interior un cap coronat i un peu que és una font. La perplexitat que desvetlla el sentit literal d'aquesta nova imatge composta s'esvaeix del tot si el lector segueix totes les fases de les successives significacions al-legòriques destinades a preparar el salt cap al sentit transcendent.

Llull proposa tres relats al-legòrics: al capítol 354, «Lo contrast qui és enfre el cors e l'ànima»; al 355, «La carrera de paradís» i al 356, «La celestial glòria e la infernal pena». El primer és una psicomàquia en què hi ha tres donzelles que representen les tres potències de l'ànima i un arbre que significa el coneixement. També apareix una bèstia que fa referència a l'home, compost de cos i ànima, amb una escenificació dels vicis i de les virtuts. L'aliança entre les potències de l'ànima intel-lectiva i les virtuts és facil de descobrir i també és transparent l'al-lusió al principi de generació i corrupció que governa el món 
material. ${ }^{16}$ «Lo contrast qui és enfre lo cors e l'ànima» és una elaboració literària complexa, que aprofita materials de molt diversa procedència: la disputa entre l'ànima i el cos de la tradició romànica, les imatges apocalíptiques d'algunes de les bèsties que es descriuen i el conte de l'unicorn de la llegenda de Barlaam i Josafat. ${ }^{17}$ La cura dels detalls i l'ambició significativa no desmereixen d'obres tan conegudes i imitades de l'al-legoria llatina medieval com l'Anticlaudianus d'Alà de Lille. En les obres posteriors de Llull no es tornen a trobar esments del mètode contemplatiu basat en l'al-legoria en els termes exposats als capítols 352-357 del Llibre de contemplació.

Convé observar que les tres peces de ficció al-legòrica del Llibre de contemplació dels capítols 354, 355 i 356 s'ofereixen al lector per tal que les interpreti d'acord amb les claus que ofereix ell mateix als capítols 352 i 353. És un primer intent d'autocomentari que sol-licita la interacció del públic.

El Coment del Dictat està construït com la glossa completa d'una composició en vers escrita per ell mateix, el Dictat de Ramon (Barcelona-Mallorca, 1299-1300). ${ }^{18} \mathrm{El}$ conjunt, composició poètica i glossa, s'ha conservat en català, en una traducció llatina i en una de castellana. ${ }^{19}$ L'operació intel.lectual de comentar en vulgar una composició poètica escrita pel mateix autor del comentari és del tot singular a les acaballes del segle xiıI: només la trobem documentada al Convivio de Dante Alighieri, dels anys 1304-1307. A partir de l'autocomentari del seu Dictat, el Coment, Llull va elaborar un altre text que només s'ha conservat en versió llatina, el Compendiosus tractatus de articulis fidei catholicae. Es tracta d'un opuscle que, tot i tenir el mateix contingut del Coment del Dictat, es presenta en una disposició expositiva que esborra completament la singularitat formal de l'obra original: han desaparegut els versos i les fórmules d'enllaç, pròpies d'una glossa seguida.

El Dictat de Ramon, que és a la base de l'operació de l'autocomentari, és escrit en versos apariats de vuit síl.labes, les noves rimades de la tradició narrativa romànica. Llull aprofita l'estructura binària dels versos apariats per produir sèries de dístics. Cada dístic conté una proposició relativa a un dels sis articles centrals de fe del cristianisme, al voltant dels quals s'organitza l'obra: l'existència de Déu, la unicitat de Déu, la trinitat divina, l'encarnació de Crist, la creació del món i la resurrecció. L'autocomentari en prosa dels dístics,

16. Ramon Llull, Llibre de contemplació, a cura de Josep Enric Rubio, Barcelona: Barcino («Biblioteca Barcino», 5), 2009, p. 323-335. Remeto al fragment recollit en aquesta antologia, que és una drecera molt pràctica per accedir al monumental Llibre de contemplació.

17. Armand Llinarès, «Théorie et pratique de l'allégorie dans le Libre de contemplación, Estudios Lulianos, n. 15, 1971, p. 5-34; Josep Enric Rubio, «Un capítol en l'ús de l'al-legoria en Ramon Llull: exegesi del capítol 354 del Llibre de contemplación, SL, n. 47, 2007, p. 5-27.

18. Llull, Rims, a cura de Salvador Galmés, I, Palma de Mallorca, Comissió Editora Lul.liana ("ORL, XIX»), 1936, p. 261-274 i 275-324.

19. Versió llatina: Dictati comentum, a cura de Fernando Domínguez, ROL XIX, 1993, p. 327-406; versió castellana, Fernando Domínguez, «El Coment del dictat de Ramon Llull. Una traducción castellana de principios del siglo xv», dins Studia in honorem prof. M. de Riquer, IV, Barcelona: Quaderns Crema, 1991, p. 169-232. 
el Coment del Dictat, consisteix en el desplegament de les raons necessàries que es poden extreure de cada parella de versos per tal de produir successives demostracions de l'article de fe corresponent. Com que els dístics poden resultar obscurs, cal que el mateix Ramon amb el seu Coment en mostri el sentit fent el paper de l'«ensenyador». Demostrar els articles de la fe per raons necessàries és el cavall de batalla de totes les Arts i de la Lògica nova, i també és un tema molt present en obres de caràcter literari: només cal remetre Llibre del Gentil o al primer capítol del Fèlix. L'artifici lògic de la demostració és la reducció a l'absurd, o "demonstratio per hipotesim», que consisteix a negar la proposició que es vol demostrar i avaluar les conseqüències que se'n deriven. Si les conseqüències són impossibles, queda validada la veracitat de la sentència de partida. ${ }^{20}$ El Coment del Dictat és, en suma, una amplificació didàctica que desenvolupa i aclareix l'abast demostratiu de les successives proposicions expressades sintèticament en cada parella de versos. De fet, les noves rimades del Dictat, que es poden desglossar en dístics, estan molt a prop de la forma proverbi, i el primer recull d'aquestes unitats breus en forma de llibre són els Proverbis de Ramon, de 1296. La relació entre els dístics del Dictat i les expansions del Coment són un precedent dels proverbis i dels «recontaments» de l'«Arbre exemplifical» de l'Arbre de ciència.

El Cant de Ramon és la composició poètica lul-liana que reprèn amb més fidelitat els trets propis de la lírica trobadoresca; va ser escrit a Mallorca el 1300 , és a dir, contemporàniament a la versió llatina en forma expositiva del Coment del Dictat. El jo poètic es presenta al lector com un convertit a la penitència i dipositari d'una il.luminació salvífica, que es lamenta dels fracassos acumulats, fa acte de contrició, es reafirma en les pròpies conviccions i s'encomana fervorosament a Déu. El Cant de Ramon conté seqüències imatjades, com la dels versos 16-17, «Enfre la vinya e el fenollar / amor me pres, fe'm Déus amar». ${ }^{21}$ Un autocomentari d'aquest dístic hauria pogut extreure la significança de les imatges o especular sobre els sentits al-legòric, tropològic o anagògic de l'accepció literal. Un desenvolupament d'aquesta mena faria possible la comparació amb l'autocomentari poètic del Convivio. Però el Dictat de Ramon no és el Cant de Ramon, perquè, tot i les pinzellades autobiogràfiques del pròleg, no conté cap rastre de llenguatge poètic. La composició és del tot funcional, centrada en dos punts: l'afirmació reiterada i rotunda de la capacitat de Ramon per provar els articles de la fe i la perspectiva de l'aplicació d'aquesta capacitat demostrativa a la predicació als infidels. Cal considerar, doncs, l'insòlit gènere de l'autocomentari com un recurs literari més dels molts que Llull va experimentar al llarg de la seva obra. La coincidència en la tria amb Dante és atractiva, la realització, però, no podria ser més desconcertant.

20. Cfr. el desplegament complet de la prova de l'existència de Déu a partir de la concordança entre ésser i perfecció segons l'Art demostrativa, a Bonner, The Art and Logic, cit., p. 80-86; L'Art i la lògica, cit., p. 88-95.

21. Ramon Llull, Poesies, a cura de Josep Romeu, Barcelona: Enciclopèdia Catalana, 1988, p. 73 . 


\section{Nova retòrica i pràctica d'escriptura}

Ramon Llull va tractar diverses vegades de la retòrica en el marc de les arts liberals a les seves obres de caràcter enciclopèdic, com la Doctrina pueril i l'Arbre de ciència, $\mathrm{i}$ també va tocar alguns aspectes de la retòrica en els tractats de predicació, però el que crida més l'atenció és la monografia que porta el títol de Retòrica nova i que gosa assignar quatre parts a l'antiga disciplina escolar en lloc de les cinc convencionals: ordo, pulchritudo, scientia, charitas i no inventio, dispositio, elocutio, memoria, actio. ${ }^{22}$

L'adaptació de les diverses ciències del repertori medieval a l'Art lul.liana produeix versions renovades de les disciplines. ${ }^{23}$ Per aquest procediment Llull va reformar la medicina i el dret amb diverses monografies escrites en fases successives de l'evolució de l'Art, i també es va ocupar de les arts liberals. La gramàtica, l'aritmètica i la música no van ser objecte de monografies específiques, però el 1297 va escriure un Tractatus novus de astronomia i el 1299 un Liber de geometria nova et compendiosa. ${ }^{24}$ No és gens estrany, doncs, que dediqués sengles llibres a dues disciplines del trivi, la Retòrica nova, de 1301, i la Lògica nova, de $1303 .{ }^{25}$ En aquestes monografies sobre les arts liberals, totes posteriors a 1290, és a dir, derivades de les Arts ternàries o de la segona fase, el mètode lul.lià consisteix a aillar els principis de la disciplina tractada i investigar-los a través de les regles i les qüestions de l'Ars inventiva o de la Taula general. A la Retòrica nova Llull es limita a presentar al lector una doctrina reduïda i perfectament coherent sense entrar en polèmica amb cap precedent. El primer estudi modern de la Retòrica nova lul.liana va posar en evidència la importància que Llull atribueix als exemples i els proverbis; ${ }^{26}$ posteriorment la crítica ha afinat les relacions del text de Llull amb la tradició i s'ha decantat a considerar aquesta monografia com una aportació teòrica a la predicació. ${ }^{27}$ Els curadors de la darrera edició comentada de la Retòrica nova de la TORL suggereixen, en canvi, que Llull investiga els principals trets que considera necessaris per a la producció de tota mena de parlaments: el terme llatí és sermones, en l’accepció més general.

22. Cfr. la introducció a Llull, Retòrica nova, TORL.

23. Lola BADIA, «La ciència a l'obra de Ramon Llull», dins Joan Vernet i Ramon PARÉs (a cura de), La Ciència en la Història dels Pä̈sos Catalans, I. Dels Àrabs al Renaixement, BarcelonaValència: Institut d'Estudis Catalans-Universitat de València, 2004, p. 403-442.

24. Josep Enric Rubio, "The Natural Realm», dins Alexander Fidora i Josep Enric Rubio (a cura de), Raimundus Lullus. An Introduction to His Life, Works and Thought, 2008, p. 311-362 (ROL, Supplementum Lullianum, II).

25. Bonner, The Art and Logic, cit., p. 188-255; L'Art i la logica, cit., p. 211-286.

26. Jordi Rubió i Balaguer, «La Rhetorica nova de Ramon Llull», dins ID., Ramon Llull i el lul.lisme, Barcelona: Generalitat de Catalunya-Publicacions de l'Abadia de Montserrat, 1985, p. 202-233.

27. Mark D. Johnston, The Evangelical Rhetoric of Ramon Llull. Lay Learning and Piety in the Christian West around 1300, New York-Oxford: Oxford University Press, 1996; ID. «The Rhetorica nova of Ramon Llull: a guide to "speaking well”", La Corónica, n. 34.2, 2006, p. $135-160$. 
Contràriament el que podria fer pensar el títol de Retòrica nova, el tractament que Llull fa d'aquesta disciplina a l'Ars generalis ultima (1305-8) és més complet i sistemàtic que no pas el de la monografia en qüestió, que al pròleg confessa escrita de corre-cuita, entremig de tasques més urgents. ${ }^{28} \mathrm{Cal}$ llegir, doncs, l'aplicació 86 del l'Art a les Cent formes, és a dir, els punts de referència bàsics per a la descripció de la realitat que es poden estudiar amb l'Art. ${ }^{29}$ La secció B es titula "Applicatio Artis generalis ad Artes particulares» i conté la reformulació artística de vint arts, ciències o disciplines particulars: s'hi compten totes les del trivi i el quadrivi, i la darrera és l'art de la memòria. A l'aplicació 86 de l'Ars generalis ultima la nova retòrica lul.liana es presenta com una "ars inventa, cum qua rhetoricus colorat et ornat sua verba». ${ }^{30}$ "Colorare» $\mathrm{i}$ «ornare» són operacions que potencien la bellesa del discurs, una noció que es combina immediatament amb la d'ordre: «Et quia ista ars est genealis, idcirco est generale subiectum ad ordinandum sua verba, videlicet, ut cum dicitur: bonitas est magna, etc.». ${ }^{31}$ Les primeres frases ben acolorides i ordenades que presenta Llull són de l'estil: «Bonus magnus et aeternus producit bonificatum, magnificatum et aeternatum». ${ }^{32}$ L'acoloriment i l'ornamentació, que constitueixen la bellesa, es regeixen per la teoria de la «vox significativa» que "patet» per la regla E de l'Art, la del «quare»:

Rhetoricus ornat cum voce significativa. Ut cum dicitur: Aprilis et Maius, qui sunt pulchriora vocabula, quam quando dicitur: October et November, eo quia significant flores et folia, et avium cantum, et renovationem temporis et rerum generabilium: October et November nequaquam. Et hoc idem potest dici de fontibus, fluminibus, rivulis, pratis et arboribus, umbris, et huiusmodi. Qui sunt pulchra vocabula secundum sensum et imaginationem. Et hoc patet per regulam E. ${ }^{33}$

Els termes abril i maig són més bells que no pas octubre i novembre perquè signifiquen la continuïtat de l'ésser i de la generació; evoquen coses belles per als sentits i la imaginació. La significació i la memòria són la clau de la retòri$\mathrm{ca}$, en el benentès que s'estableixi una diferència entre el nivell sensual i l'intellectual. Per a l'intel.lecte, en efecte, com s'explica al paràgraf 18 del capítol 359 del Llibre de contemplació el mot més bell és indiscutiblement Jesucrist, perquè significa la plenitud de l'ésser, la trinitat i l'encarnació. ${ }^{34}$ Cal subratllar que l'aplicació sistemàtica d'aquesta manera d'entendre l'acoloriment i l'ornamen-

28. Llull, Retòrica nova, TORL, p. 94-95: «Volentes ... ordinandorum ornandorumque verborum notitiam tradere ... secundum Artem generalem ... sed non valentes propter alia quaedam negotia quae vitare non possumus...".

29. Anthony Bonner i Maria Isabel Ripoll, Diccionari de definicions lul.lianes / Dictionary of Lullian Definitions, Barcelona-Palma de Mallorca: Universitat de Barcelona-Universitat de les Illes Balears («Col-lecció Blaquerna», 2), 2002, p. 20-23.

30. Ramon Llull, Ars generalis ultima, Alois Madre (ed.), ROL XIV, 1986, p. 363.

31. Ibid., p. 363.

32. Ibid., p. 364.

33. Ibid., p. 364.

34. Llull, Llibre de contemplació, cit., p. 341. 
tació de les paraules, és a dir, la seva bellesa, atorga valor estètic a frases tan poc homologables amb el llenguatge literari convencional com la que hem citat més amunt, que són plenes de termes tècnics de l'Art com ara els participis bonificat, magnificat i eternat, relacionables amb els principis correlatius, un altre dels artificis lògico-metafísics de l'Art. ${ }^{35}$ Es tracta d'uns mots que el mateix autor considera "paraules estranyes». ${ }^{36}$ Llull posa per davant la significació intel.lectual a la significació sensual i deixa de banda l'harmonia fonètica i les tradicions expressives derivades de la imitació i l'emulació de models consagrats i està en desacord amb les reflexions coetànies de Dante. Al De vulgari eloquentia Dante també proposa una teoria de la significació del llenguatge quan assenyala que hi ha tres grans temes — «tria magnalia: salus, venus, virtus»—, dels qual deriven els mots bells que els trobadors i els poetes italians han emprat en les seves composicions. ${ }^{37} \mathrm{El}$ punt de referència de l'excel.lència significativa dels «tria magnalia» dantescos són versos construïts d'acord amb les convencions de la tradició lírica. ${ }^{38}$

La retòrica lul.liana construeix una jerarquia de bellesa en la coloració o l'ornamentació del discurs que té en compte les relacions entre els trets essencials de les paraules. El terme color té una funció completament diferent dels colores de la retòrica escolar medieval, que designen les figures de pensament $\mathrm{i}$ de paraula: anàfora, antítesi, sinècdoque, metonímia. D'acord amb els seus principis, Llull desplega la seva pròpia pràctica de l'ornamentació: cal ornamentar bells subjectes amb bells accidents, lloar els amics amb termes bells i blasmar els enemics amb termes lletjos, triar els adjectius que concorden en bellesa amb els termes i recórrer a la lítote per no desfer l'harmonia si es blasma un subjecte bell. Els tres graus de comparació de l'adjectiu (positiu, comparatiu, superlatiu) donen molt de joc en l'embelliment del discurs i també la diferent dignitat dels oficis (clergues, cavallers, burgesos, pagesos). L'ordre de les paraules també és indici de bellesa si segueix adequadament la disposició jeràrquica. A la Retòrica nova es diu, concretament, que no fa bonic barrejar termes masculins amb femenins i neutres, perquè els primers són més nobles si s'aplica el triangle diferència, concordança i contrarietat. ${ }^{39}$

El pròleg de la Retòrica nova introdueix el concepte de «pulchritudo» en la definició de la disciplina; a l'aplicació 86 de l'Ars generalis ultima la noció de bellesa només apareix com a adjectiu que acompanya els termes que contribueixen a la coloració i l'ornamentació escaients.

35. Jordi GaYÀ, La teoría luliana de los correlativos. Historia de su formación conceptual, Palma de Mallorca, 1979.

36. Cfr. la taula final de l'Art amativa / Ars amativa, que explica el sentit de termes tècnics com amativa, amància, amabundus, animal, actu, acció, etc., Ramon Llull, Art amativa, a cura de Salvador Galmés, ORL XVII, 1933, p. 389-398 i Ramon Llull, Ars amativa boni, a cura de Marta M.M. Romano, ROL XXIX, 2004, p. 437-432.

37. II.II.7-8, Alighieri, Opere, cit., p. 1386-1398.

38. Fins i tot els mots «irsuts» de Dante es justifiquen per la forma poètica: «sovramagnificentisssimamente, quod endecasillabum est» (II.vir.6, Alighieri, Opere, cit., p. 1468).

39. Cfr. el paràgraf 170, Llull, Retòrica nova, TOLR, p. 184. 
No hi ha, doncs, una reflexió específica sobre la bellesa del discurs: Llull tracta sempre molt sumàriament de la retòrica perquè la tasca missionera passa per davant d'una disciplina instrumental, que és clarament menys necessària que la lògica. La superioritat de la lògica en relació a la retòrica s'explica a través d'una semblança a la qüestió 179, a les fulles de l'"Arbre humanal»: la retòrica pot desvetllar la pietat d'un príncep, però la lògica és la que guia l'exercici de la justícia. ${ }^{40}$ Llull, tanmateix, es disposa a donar consells pràctics per produir discursos — «sermones»— de qualsevol matèria que siguin bells; i són bells si duen a terme adequadament la funció comunicativa: si el parlant i l'oient arriben feliçment al fi comú que es proposen, el discurs serà bell. La bellesa en la retòrica, doncs, depèn de l'eficàcia.

Les quatre parts de la Retòrica nova (ordre, bellesa, ciència i caritat) s'adeqüen perfectament a la teoria exposada a l'aplicació 86 de l'Ars generalis ultima: en aquesta l'ordre és la primera condició de la coloració i l'ornamentació del discurs. La bellesa s'obté amb determinats procediments operatius que Llull es preocupa de desenvolupar, com es veurà tot seguit. La ciència és l'Art de Ramon, fonament de totes les disciplines, que s'estudia en relació amb la retòrica repassant els principis i les regles; la caritat és la condició moral de la bondat de qualsevol discurs: «Ille qui loquitur in caritate verba pulchrificat». ${ }^{41}$ Es tracta d'un lloc comú present arreu almenys des del segle XII. ${ }^{42}$

L'apartat de l'ordre és el que proposa uns consells que s'assemblen més a les Artes dictaminis medievals: cal començar amb un exordi seguit d'un exemple, continuar amb l'exposició de la matèria i elaborar unes conclusions. En canvi, la bellesa, una noció que no forma part de l'estructura de la retòrica escolar, "est unum ex decorantibus et ornantibus verba». ${ }^{43}$ Aquesta bellesa, segons Llull, depèn de set factors: les paraules, els principis, les comparacions, els exemples, la dignitat de qui parla, la coherència entre la bellesa i la lletgesa en l'organització del discurs, i l'ús de proverbis. Les paraules i els principis bells es regeixen per la significació, i les comparacions belles s'han de construir segons la jerarquia de les significacions, sobretot si s'utilitzen els graus de comparació de l'adjectiu. La dignitat de qui parla depèn de com es presenta físicament i de com controla els moviments del cos; l'organització del discurs també es regeix per la jerarquia de les significacions. Les possibilitats que Llull proposa per a cada una d'aquestes maneres de produir bellesa són mínimes i poc variades; en canvi, l'apartat relatiu als exemples i als proverbis proporcio-

40. Ramon Llull, Arbre de ciència, a cura de Tomàs i Joaquim Carreras Artau, dins OE, I, Barcelona: Selecta, 1957, p. 835; Ramon Llull, Arbor scientiae, Pere Villalba (ed.), ROL XXVI, 2000, p. 1145.

41. Llull, Retòrica nova, TOLR, p. 204.

42. Joan de Salisbury al Metalogicus (1159) recorda les lliçons de gramàtica, retòrica i comentari dels auctores de Bernat de Chartres: la pràctica de la imitació per escrit dels models és la base de l'aprenentatge: «nihil utilius ad eloquentiam, nihil expeditius ad scientiam, et plurimum confert ad vitam, si tamen hanc sedulitatem regit charitas, si in profectu litterario servetur humilitas» (I, 24, PL CXCIX, c. 856).

43. Llull, Retòrica nova, TOLR, p. 110. 
na vint-i-quatre mostres de formes narratives breus i cinquanta formes sentencioses, totes de temàtica molt diversa.

No és difícil posar en relació aquest desplegament de materials retòrics amb els trenta anys d'experiència d'escriptura de Llull (1271-1301). El descobriment de la manera de transformar la ciència en literatura ja havia estat portat a la pràctica a l' "Arbre exemplifical» de l'Arbre de ciència, constituït per «recontaments» i exemples, generats per la matèria dels «Arbres» de l'obra dedicats a les diverses disciplines i sabers. ${ }^{44}$ Les formes breus havien arribat ja a la total autonomia en els reculls de proverbis iniciats el $1296 \mathrm{amb}$ els Proverbis de Ramon. ${ }^{45}$ Precisament la Retòrica nova dóna vida a aquest instrument expressiu que desenvolupa la concentració i la intensitat, d'acord amb els darrers «experiments» de l'expressió literària lul-liana.

Mereix una consideració a part la mostra de vint-i-quatre exemples de l'apartat 4 de la segona part de la Retòrica nova, la que tracta de la bellesa. ${ }^{46}$ Els cinc primers exemples en realitat són consideracions de caràcter teològic que influeixen en la natura angèlica i en la intenció final de l'home. El sisè tracta d'un bisbe hipòcrita i el setè de les propietats dels planetes. Els tres següents es fonamenten en el comportament i la natura dels animals: lleó, àliga, peix. Seguidament Llull es recorda de tres històries d'animals extretes de faules orientals que ell mateix ha fet servir en obres seves: la faula de l'agró, el cranc i els peixos, que s'explica al capítol 40 del Fèlix dintre del «Llibre de les bèsties», i la faula dels micos que volien encendre foc amb una lluerna, que Llull havia ja explicat al Romanç d'Evast e Blaquerna. ${ }^{47}$ És especialment significatiu que al paràgraf 50 Llull és recordi també de la faula de la guineu («vulpes») i expliqui la trama del «Llibre de les bèsties» i comenci dient: «Ex antiquorum narratione acceptum est quod una vulpes rogavit leonem, regem bestiarum, ut eam de domo sua et de suo consilio faceret». ${ }^{48}$ L'espai destinat a explicar aquests exemples de tema animal és més generós que els altres. Els breus comentaris sobre la bellesa que es desprenen d'haver-los explicat es poden llegir com una autèntica forma d'autocomentari, atès que Llull està repassant materials que ha fet servir en les seves pròpies obres literàries. Són

44. Robert D.F. Pring-Mill, «Els "recontaments" de 1 "Arbre exemplifical” de Ramon Llull: la transmutació de la ciència en literatura», dins ID., Estudis sobre Ramon Llull, Barcelona: Publicacions de l'Abadia de Montserrat, 1991, p. 307-317.

45. Francesc Tous Prieto, «"Breus proposicions que contenen molta sentència”: els proverbis lul.lians i les "formes sentencioses"”, $S L$, n. 51, 2011, p. 77-98.

46. Llull, Retòrica nova, TOLR, p. 122-143. Per a la singularitat de la teoria lul.liana de l'exemple i del seu ús, cfr. José AragüÉs Aldaz, “Exempla inquirere et invenire”. Fundamentos retóricos para un análisis de las formas breves lul-lianes», dins Carlos Alvar i José Manuel Lucía Megías (a cura de), La literatura en la época de Sancho IV. Actas del Simposio de 1994, Alcalá de Henares: Universidad de Alcalá de Henares, 1996, p. 289-311; Albert G. Hauf, «Sobre l'Arbor exemplificalis», dins Fernando Domínguez Reboiras, Pere Villalba Varneda i Peter Walter (a cura de), Arbor Scientiae: der Baum des Wissens von Ramon Lull, Turnhout: Brepols, 2002, p. 303-342.

47. Armand Llinarès, «Les singes, le ver luisant et l'oiseau», Romania, n. 108, 1989, p. 97-106.

48. Llull, Retòrica nova, TOLR, p. 134. 
els únics materials literaris que conserven encara avui la seva eficàcia comunicativa: Llull l'encertava considerant-los bells, si la bellesa és una forma d'eficàcia.

Segueixen un exemple que tracta de les tres potències de l'ànima i un altre sobre les relacions de concordança i contrarietat entre les propietats dels quatre elements, molt proper al «recontament» de les arrels de l'«Arbre exemplifical» de l'Arbre de ciència. Després vénen cinc exemples més de tema vegetal i quatre que parlen dels metalls. Tots aquests nou exemples finals evoquen qüestions de filosofia natural que Llull ha tractat als llibres cinquè i sisè del Fèlix o Llibre de meravelles. Llegim l'exemple següent:

Arbores producunt ramos, folia et flores, propter fructum, qui est nobilior inter arborum partes. Nam fructus magis servit hominibus quam alia pars arboris et in fructu arboris species reservatur. ${ }^{49}$

Aquest exemple correspon a una de les semblances que articula el capítol 31 del Fèlix, que tracta de la generació i de la corrupció, i també cal posar-lo en relació amb el darrer «recontament» del fruit de l'«Arbre exemplifical». ${ }^{50}$ Novament els comentaris de Llull sobre la bellesa dels exemples de filosofia natural que proposa es poden llegir sense exagerar com un exercici d'autocomentari. La secció sobre l'exemple es tanca amb un resum de la doctrina sobre la producció d'exemples a partir dels continguts doctrinals expressada al pròleg de l'«Arbre exemplifical»:51

Secundum exempla superius enarrata, tradita est doctrina, per quam potest homo suis verbis conferre decorem narrando pulchra exempla et ipsa fini verborum cui conveniunt applicando. Quae exempla potest homo inquirere et invenire secundum doctrinam quam dedimus et ea narrare et per illa alia similia de diversis materiis, prout necesse fuerit, invenire. ${ }^{52}$

L'any 1300, abans d'emprendre el viatge a Xipre, on va redactar en català l'original perdut de la Retòrica nova, Llull, a Mallorca, va escriure el Cant de Ramon. Als vv. 65-66 fa un acte de contrició per la gosadia d'haver escrit tants llibres: «e tant fort són pecador, / e són de llibres trobador»: ${ }^{53}$ la retòrica nova que proposa Ramon Llull podria ser el resultat d'un llarg examen de consciència sobre aquesta activitat, la de «trobar» llibres complementària de l'Art, que no s'ha d'apartar d'un ordre que produeix bellesa si comunica la ciència amb caritat.

49. Ibid., p. 138.

50. Pel al capítol 31 del Fèlix, cfr. Badia, Santanach i Soler, «Ramon Llull», cit., en premsa i per al recontament del fruit de l' «Arbre exemplifical», Lola BADIA, «La caiguda dels greus i la digestió dels remugants: variacions lul-lianes sobre l'experiència del coneixement", dins Pep Valsalobre i August Rafanell (a cura de), Estudis de Filologia Catalana. Dotze anys de l'Institut de Llengua i Cultura Catalanes, Secció Francesc Eiximenis, Girona-Barcelona: Universitat de Girona-Publicacions de l'Abadia e Montserrat, 1999, p. 153-173.

51. Cfr. Pring-Mill, "Els "recontaments"», cit., BADIA, "Literature as an ancilla Artis», cit.

52. Llull, Retòrica nova, TOLR, p. 142.

53. Llull, Poesies, cit., p. 77. 